\title{
DUKUNGAN SOSIAL DENGAN KECEMASAN PASIEN STROKE DI RUMAH SAKIT STROKE NASIONAL BUKITTINGGI
}

\author{
SOCIAL SUPPORT WITH ANXIETY OF STROKE \\ PATIENTS IN HOSPITALS STROKE NATIONAL \\ BUKITTINGGI
}

\author{
Febria Syafyu Sari
}

Akademi Keperawatan Nabila Padang Panjang

Jln.DR.Khamarullah no.1 Bukit Surungan Padang Panjang HP: 082174518892

Email : febrina_250288@yahoo.com, febrina914@gmail.com

Naskah Masuk: 16-04-2019

Naskah Diterima: 01-05-2019

Naskah Disetujui: 07-06-2019

\begin{abstract}
Stroke can affect the whole body such as paralysis, cognitive deficits, speech difficulties, emotional difficulties, pain, and problems in daily life. The recovery process in post-stroke patients take a long time and also require social support because they are not able to solve their own problems. Data WHO (2012) show every years as many 17 million cause of death in the world because of stroke. Anxiety is a feeling of fear that is not clear and is not supported by the situation. When we feel anxious, the individual feels uncomfortable, afraid or may have a bad feeling. Social support for the sufferers urgently needed as long as the sufferers still able to understand the meaning of that support as an advocate for live.This study aimed to determine the social support relation with anxienty stroke patient. This research is a CrossSectional with Accidental Sampling method. This research do at National Stroke Hospital Bukittinggi with 160 respondens. The statistical test used is Chi-Square. The result of statistical test showed a significant between the social support relation with anxiety stroke patient with p-value $=0,000(\alpha \leq$ $0,05)$.The hospital is expected to urge the family to more actively in volve in caring for stroke patients and provide counseling to them in order to better understand the importance of any rehabilitation program recommended.
\end{abstract}

Keywords: Social Support, Anxiety

\begin{abstract}
ABSTRAK
Stroke merupakan penyakit yang berpengaruh pada seluruh tubuh seperti kelumpuhan, defisit fungsi kognitif, kesulitan bicara, kesulitan emosional, kesakitan dan masalah dalam kehidupan sehari-hari. Untuk proses pemulihan/rehabilitasi pasca stroke membutuhkan dukungan sosial. Data WHO (2012), menunjukan bahwa setiap tahun sekitar 17 miliar kasus kematian di dunia disebabkan karena stroke. Cemas adalah perasaan takut yang tidak jelas dan tidak didukung oleh situasi. Ketika merasa cemas penderita merasa tidak nyaman, takut atau mungkin memiliki firasat yang buruk. Dukungan keluarga bagi pasien stroke sangat diperlukan selama pasien masih mampu memahami makna dukungan tersebut sebagai penyokong kehidupannya. Tujuan penelitian untuk mengetahui hubungan dukungan sosial dengan kecemasan pasien stroke. Penelitian ini merupakan cross-sectional dengan menggunakan metode sampling accidental. Penelitian ini dilakukan di Rumah Sakit Stroke Nasional Bukittinggi dengan 160 responden. Uji statistik yang digunakan chi-square. Hasil uji statistik menunjukan bahwa adanya hubungan yang signifikan antara dukungan sosial dengan kecemasan pasien stroke dengan nilai $p$-value = $0,000(\alpha \leq 0,05)$. Bagi rumah sakit diharapkan agar lebih aktif melibatkan keluarga dalam merawat pasien stroke serta memberikan penyuluhan kepada keluarga agar lebih memahami tentang penting setiap program rehabilitasi.
\end{abstract}

Kata Kunci : Dukungan Sosial, Kecemasan 
PENDAHULUAN

Stroke dapat menyebabkan ketergantungan usia makin meningkat. Perubahan yang sering terjadi pada penderita stroke antara lain kelumpuhan, perubahan mental dapat menpengaruhi pikiran dan dampak emosional, hilangnya sensori akibat ketidakmampuan bicara, kesulitan berjalan, berpakaian, mengendalikan buang air besar dan kecil, mandi, makan, sulit melakukan gerakan seharihari, perubahan pribadi berupa halusinasi dan depresi, khususnya bila hanya berbaring di tempat tidur sehingga kebutuhan ADL (Activity Daily Living) tidak terpenuhi, keadaan seperti ini secara langsung membuat angka ketergantungan terhadap keluarga akan semakin bertambah (Sylvia, S, 2009).

Keadaan psikologis yang negatif pada penderita stroke tersebut disebabkan karena adanya perubahan pada ADL (Activity Daily Living), misalnya dalam urusan rumah tangga, pemenuhan kebutuhan nutrisi, pemenuhan kebutuhan mobilisasi, dan kelelahan (Van Den Port, dalam Rohardja, Komariah \& Adiningsih, 2012).
World Health Organization (WHO) (2012), kematian akibat stroke sebesar (51\%) disebabkan oleh tekanan darah tinggi. Selain itu diperkirakan sebesar (16\%) kematian stroke disebabkan tingginya kadar glukosa dalam darah dalam tubuh (Riko dkk, 2008). Setiap tahun terjadi hampir 17 miliar kasus stroke baru di seluruh dunia, jumlah kematian akibat kasus stroke 5,5 miliar atau $(29 \%)$ sedangkan yang dapat hidup (89\%). Dari populasi di dunia jumlah stroke terbanyak adalah stroke iskemik sebanyak (80\%) stroke hemoragik sebanyak $(10 \%: 15 \%)$ dan sub arachnoid hemoragik sebanyak (5\%) rata-rata umur yang terkena gangguan stroke adalah usia 60 tahun atau lebih (WHO, 2010). Di Amerika Serikat setiap tahunnya terdapat sekitar 200.000 kasus kematian yang disebabkan oleh stroke, di perkirakan sekitar 2 juta orang Amerika Serikat menderita gangguan neurologis akibat stroke, sekitar (50\%) dari orang dewasa yang dirawat dirumah sakit syaraf disebabkan oleh suatu penyakit pembuluh darah ( Susanto, 2010).

Prevalensi stroke di kawasan Asia Tenggara seperti Singapura sebanyak $(4,05 \%)$ penduduk, sedangkan di Thailand sebanyak 690 per 100.000 
penduduk Kemenkes RI, 2013). Prevalensi stroke tahun (2015), stroke merupakan pembunuh nomor satu di RS Pemerintah di seluruh Indonesia. Diperkirakan 550.000 penduduk yang terkena stroke insiden mengenai populasi usia lanjut yang berusia 75-84 tahun sekitar 10 kali dari populasi 55-64 tahun. Dari jumlah tersebut, sebanyak (30\%) dapat pulih kembali (35\%), mengalami gangguan fungsional ringan sampai sedang dan (35\%) mengalami gangguan fungsional berat ( Purnomo, 2010 ).

Dampak yang ditimbulkan dari penyakit stroke seperti dampak psikologis pada keluarga pasien, salah satunya keluarga akan mengalami kecemasan. Keluarga merasa cemas dengan perkembangan keadaan klien, pengobatan maupun perawatan (Nursalam, 2009).

Gangguan kecemasan adalah salah satu gangguan mental yang umum dengan prevalensi seumur hidup yaitu sebanyak (16\%-29\%) Katz, et al., 2013). Dilaporkan bahwa perkiraan gangguan kecemasan pada dewasa muda di Amerika Serikat adalah sekitar $(18,1 \%)$ atau sekitar 42 juta orang hidup dengan gangguan kecemasan seperti gangguan panik, gangguan pasca trauma ( Duckworth, 2013). Sedangkan gangguan terkait jenis kelamin dilaporkan bahwa prevalensi seumur hidup wanita sebesar (60\%) lebih tinggi dibandingkan pria (NIMH dalam Donner \& Lowry, 2013).

Di Indonesia prevalensi gangguan kecemasan menurut Riskesdas pada tahun (2013) menunjukan bahwa sebesar (6\%) untuk usia 6 tahun ke atas atau sekitar 14 juta penduduk di Indonesia mengalami gangguan mental emosional yang di tunjukan dengan gejala-gejala kecemasan dan depresi ( Depkes, 2014). Berdasarkan hasil penelitian tersebut diketahui bahwa setiap orang dapat mengalami kecemasan baik cemas ringan, sedang, atau berat ( Suyanto, et al., 2009).

Penyebab kecemasan dikemukan oleh Zakiah Daradjat (dalam Khoil Lur Rohman, (2010) yaitu, rasa cemas yang timbul akibat melihat bahaya yang mengancam dirinya. Kecemasan ini lebih dekat dengan rasa takut, karena sumber nya terlihat jelas di dalam pikiran. Cemas karena merasa berdosa atau bersalah, karena melakukan hal-hal yang berlawanan dengan keyakinan atau hati nurani. Kecemasan ini sering pula menyertai gejala-gejala gangguan 
mental, yang kandang- kandang terlihat dalam bentuk yang umum. Kecemasan berupa penyakit dan terlihat dalam beberapa bentuk. Kecemasan ini disebabkan oleh hal yang tidak jelas dan tidak ada berhubungan dengan apapun yang terkandang disertai dengan perasaan takut yang mempengaruhi keseluruhan kepribadian.

Dampak dari dukungan sosial, dapat memberikan kenyamanan fisik dan psikologis kepada individu, hal tersebut dapat dilihat dari dukungan sosial mempengaruhi kejadian dan efek dari keaadaan cemas. Kondisi ini dijelaskan oleh Sarfino (dalam Rahmawati, 2013), bahwa interaksi dengan orang lain dapat memodifikasi atau mengubah presepsi individu mengenai kejadian tersebut, dan mengurangi potensi munculnya stress.

Dampak stroke dapat bersifat fisik, dan psikologis. Dampak fisik paling khas adalah paralisis, kelemahan, hilangnya sensasi di wajah, lengan, atau tungkai di salah satu sisi tubuh, kesulitan berbicara atau memahami (tanpa gangguan pendengaran), kesulitan menelan, dan hilangnya sebagian penglihatan di salah satu sisi (Feigin, 2007).
Adanya kecenderungan pasien stroke mengalami kecemasan dalam dirinya, hal yang sangat diperlukan oleh pasien stroke adalah peran keluarga. Peran keluarga akan membantu proses perawatan pasien untuk dapat sebaik mungkin penderita stroke dapat melakukan aktivitas kembali meskipun tidak sepenuhnya kembali normal seperti sebelum stroke. Menurut Sugono (2008), peran keluarga adalah ikut ambil bagian dalam suatu kegiatan, keikutsertaan secara aktif, partisipasinya dalam perawatan anggota keluarga dalam merawat pasien.

Dukungan sosial pada umumnya menggambarkan pengaruh yang dapat ditimbulkan oleh orang lain seperti, keluarga, sahabat dan orang-orang terdekat maupun masyarakat. Bantuan ini diberikan dengan tujuan agar penderita merasa diperhatikan, disayangi, dicintai dan menimbulkan sikap menerima keadaan dirinya dengan perasaan senang, seperti yang diungkapkan oleh Chaplin (2004), berpendapat bahwa penerimaan diri merupakan rasa puas pada kualitas dan bakat, serta pengakuan akan keterbatasan diri. Pengakuan akan keterbatasan diri ini tidak diikuti dengan perasaan malu ataupun bersalah. 
Hasil survei awal yang dilakukan oleh peneliti di Rumah Sakit Stroke Nasional Bukittinggi pada tanggal 10 November 2017 Jumlah pasien stroke pada tahun 2017 adalah 2140 orang (Rekam Medis, 2017)

Dari hasil wawancara dengan 15 penderita stroke mengatakan keluarganya jarang menjenguk saat di rawat di Rumah Sakit Stroke Nasional Bukittinggi, penderita stroke mengatakan keluarganya sangat penting bagi dirinya saat ini, tapi sekitar 5 orang keluarga menjenguk ke Rumah Sakit Stroke Nasional Bukittinggi, dan penderita mengatakan teman sabaya dan masyarakat juga sangat penting dalam dirinya untuk memberikan dukungan, tapi sekitar 7 orang yang pergi menjenguk saat dia di rawat. 3 penderita lagi mendapatkan dukungan penuh dari keluarga, teman sabaya, dan masyarakat.

Berdasarkan data penderita stroke diatas dari tahun ke tahun meningkat. Hasil wawancara 10 orang perawat diruangan rawat Inap A Neurologi Rumah Sakit Stroke Nasional Bukittinggi mengatakan banyak penderita stroke yang mengalami kecemasan. Hasil observasi dari 15 orang penderita stroke di ruangan rawat, keseluruhan mengalami kecemasan yang telah di observasi pada tanggal 30 November 2017

Dari data diatas, dukungan sosial belum menjadi salah satu penangan kecemasan pasien stoke sehingga perlu diteliti. Adapun tujuan dari penelitian adalah diketahui hubungan dukungan sosial dengan kecemasan pasien stroke.

\section{METODOLOGI}

Metode penelitian yang digunakan dalam penelitian ini adalah deskriktif korelasional dengan mengunakan desain Cross-Sectional (Sugiyono, 2013).

Populasi dalam penelitian ini adalah penderita Stroke yang di ruangan rawat inap Rumah Sakit Stroke Nasional Bukittinggi. Pada penelitian ini sampel diambil secara Random Sampling. (Sugiyono, 2013). Besar sampel yang di gunakan dalam penelitian ini menurut rumus Lameshow 1997, (dalam Rossa 2016) adalah 160 sampel

Penelitian dilaksanakan di ruangan Neurologi Rumah Sakit Stroke Nasional Bukittinggi pada bulan Juli 2018. Setelah peneliti mendapatkan izin penelitian dari Kantor Pelayanan Keperawatan di Rumah Sakit Stroke Nasional Bukittinggi, kemudian 
peneliti menyampaikan kepada kepala ruangan Neurologi Rumah Sakit Stroke Nasional Bukittinggi untuk diketahui dan memulai penelitian.

Teknik pengumpulan data menggunakan kuesioner dengan cara membagikan kuesioner kepada pasien stroke yang ada di Rumah Sakit Stroke Nasional Bukittinggi. Dimana responden diminta mengisi lembaran pertanyaan sesuai dengan petunjuk yang ada kuesioner terdiri dari dua bagian. Kuesioner tentang dukungan sosial.

\section{HASIL DAN PEMBAHASAN}

Tabel 1. Distribusi Data Demografi Responden
Lembar penyataan berisikan kuesioner terhadap tindakan penelitian yang diisi oleh responden menggunakan tanda checklist $(\sqrt{ })$ pada tabel selalu, sering, jarang, dan tidak pernah. Kuesioner tentang tingkat kecemasan pasien stroke Lembar penyataan berisikan kuesioner frekuensi tingkat kecemasan pasien stroke ringan, sedang, berat, sangat berat menggunakan tanda checklist $(\sqrt{ })$ Hamilton Rating Scale for Anxiety (HRS-A).

\begin{tabular}{ccc}
\hline Jenis Kelamin & Frequency (f)) & Persentase (\%) \\
\hline Perempuan & 93 & 41,9 \\
Laki-laki & 67 & 58,1 \\
\hline Pendidikan & Frequency (f)) & Persentase (\%) \\
\hline SD & 7 & 4,4 \\
SMP & 41 & 25,6 \\
SMA & 105 & 65,6 \\
Sarjana & 7 & 4,4 \\
\hline Pekerjaan & Frequency (f)) & Persentase (\%) \\
\hline Petani & 98 & 61,2 \\
PNS & 8 & 6,9 \\
Pegawai Swasta & 11 & 2,5 \\
Wiraswasta & 4 & 24,4 \\
Ibu RT & 39 & 100,0 \\
\hline Penghasilan & 160 & Persentase (\%) \\
\hline <p.800.000 & 23 & 85,6 \\
\hline Rp.1.500.000 & Frequency (f)) & 14,4 \\
\hline Total & 137 & $1 \%$ \\
\hline
\end{tabular}

Sumber : hasil pengolahan data 2018 
Berdasarkan tabel diatas dari 160 responden, responden yang paling banyak adalah berjenis kelamin perempuan yaitu 93 orang $(58,1 \%)$, pendidikan terahkir responden yang paling banyak yaitu SMA yaitu 105 orang $(65,6 \%)$, selanjutnya pekerjaan responden yang paling banyak yaitu petani sebanyak 98 orang $(61,2 \%)$ dan penghasilan responden < Rp.800.000 perbulan adalah yang paling banyak yaitu 137 orang $(85,6 \%)$.

Tabel 2. Distribusi Frekuensi Dukungan Sosial pada Pasien Stroke

\begin{tabular}{llcc}
\hline No & Dukungan Sosial & Jumlah $(\boldsymbol{f})$ & Persentase $\%$ \\
\hline $\mathbf{1}$ & Kurang & 8 & 5 \\
$\mathbf{2}$ & Cukup & 86 & 53.8 \\
$\mathbf{3}$ & Tinggi & 66 & 41.2 \\
\hline & Jumlah & $\mathbf{1 6 0}$ & $\mathbf{1 0 0 , 0}$ \\
\hline
\end{tabular}

Sumber : hasil pengolahan data 2018

Berdasarkan tabel diatas, diketahui mendapat dukungan sosial yang cukup bahwa lebih dari sebagian responden yaitu sebanyak 86 responden (53.8\%).

Tabel 3. Distribusi Frekuensi Kecemasan pada Pasien Stroke

\begin{tabular}{cccc}
\hline \multirow{2}{*}{ No } & Tingkat Kecemasan & Jumlah $(\boldsymbol{f})$ & Persentase $\%$ \\
\hline $\mathbf{1}$ & Ringan & 64 & 40 \\
$\mathbf{2}$ & Sedang & 88 & 55 \\
$\mathbf{3}$ & Berat & 8 & 5 \\
\hline & Jumlah & $\mathbf{1 6 0}$ & $\mathbf{1 0 0 , 0}$ \\
\hline
\end{tabular}

Berdasarkan tabel diatas, diketahui bahwa

kecemasan tingkat sedang yaitu 88 orang lebih dari sebagian responden merasakan $(55 \%)$.

Tabel 4. Distribusi Frekuensi Hubungan Dukungan Sosial dengan Kecemasan pada Pasien Stroke

\begin{tabular}{|c|c|c|c|c|c|c|c|c|c|}
\hline \multirow{3}{*}{ Dukungan Sosial } & \multicolumn{6}{|c|}{ Tingkat Kecemasan } & & \multirow{3}{*}{ p Value } \\
\hline & \multicolumn{2}{|c|}{ Ringan } & \multicolumn{2}{|c|}{ Sedang } & \multicolumn{2}{|c|}{ Berat } & & & \\
\hline & $\mathbf{N}$ & $\%$ & $\mathbf{N}$ & $\%$ & $\mathbf{N}$ & $\%$ & $\mathbf{N}$ & $\%$ & \\
\hline Cukup & 31 & 36 & 55 & 64 & 8 & 5 & 99 & 100 & 0,000 \\
\hline Tinggi & 33 & 50 & 33 & 50 & 0 & 0 & 66 & 100 & \\
\hline Total & 64 & 40 & 88 & 55 & 8 & 5 & 165 & 100 & \\
\hline Sumber & $:$ & & hasi & & per & $a n$ & & & 2018 \\
\hline
\end{tabular}

Berdasarkan tabel diatas diketahui hasil pasien stroke diperoleh ada sebanyak analisis hubungan antara dukungan 99 responden yang mendapatkan sosial dengan tingkat kecemasan pada dukungan sosial yang cukup merasakan 
kecemasan sedang 55 responden (64\%), Sedangkan penderita stroke yang yang mendapat dukungan sosial yang tinggi ada masing-masing 33 responden $(50 \%)$ yang merasakan kecemasan ringan dan sedang.

\section{Dukungan Sosial}

Hasil penelitian didapatkan bahwa lebih dari sebagian responden mendapat dukungan sosial yang cukup yaitu $(53,8 \%)$. Menurut Gonollen \& Bloney (dalam Muzdalifah, 2009), dukungan sosial adalah derajat dukungan yang diberikan kepada individu khususnya sewaktu dibutuhkan oleh orang-orang yang memiliki hubungan emosional yang dekat dengan orang tersebut.

Sedangkan menurut Taylor (2009), dukungan sosial adalah pertukaran interpersonal yang diberikan oleh perhatian emosi, bantuan instrumental, penyedian informasi, atau pertolongan lainnya.

Penelitian yang dilakukan oleh Antari, dkk (2016), menunjukan dukungan sosial akan mempengaruhi kualitas hidup pada seseorang mendapat dukungan instrumental berupa dukungan bantuan dalam bentuk nyata dan material. Dukungan Informasional adalah berupa pemberian informasi yang dibutuhkan oleh individu. Dukungan emosional dan pengharga berupa perhatian dan membantu dalam penyelesaian masalah yang sedang dihadapi sebagai bentuk penghargaan positif .

Menurut penelitian yang dilakukan oleh Masyithah (2012), bentuk dukungan sosial yang diberikan oleh lingkungan sosial dapat berupa kesempatan untuk bercerita, meminta pertimbangan, bantuan nasehat dan tempat untuk mengeluh. Selain itu, lingkungan dapat memberikan dukungan sosial berupa perhatian, bantuan materil dan spiritual serta penghargaan dari lingkungannya. Dukungan sosial akan sangat diperlukan oleh penderita pasca stroke karena akan mengurangi ketegangan psikologis dan menstabilkan kembali emosi penderita pasca.

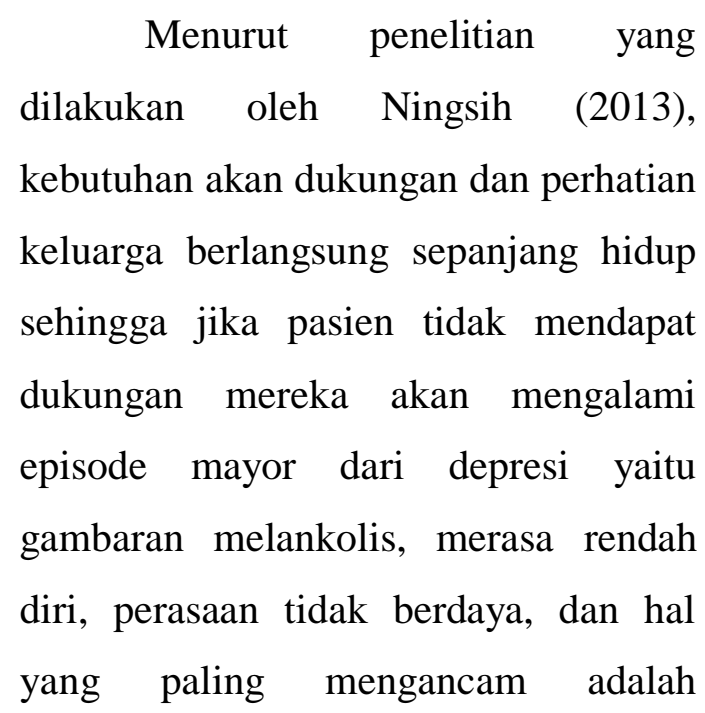

8 | Jurnal Pembangunan Nagari $\mid$ Volume 4 Nomor 1 Edisi Juni 2019 : 1 - 16 
keinginan untuk bunuh diri. Melalui dukungan keluarga, pasien akan merasa masih ada yang memperhatikan.

Penelitian ini juga didukung oleh Hasan (2013), hal ini menunjukkan bahwa dukungan sosial dengan aspekaspek yang ada didalamnya dapat dijadikan sebagai prediktor untuk memprediksi strategi koping pada penderita stroke. Secara psikologis, apabila dukungan dari lingkungan sosial penderita stroke mampu mengoptimalkan aspek emosional, penghargaan, informasi, dan instrumental berupa perhatian, nasehat, saran, pemberian pekerjaan, maka dukungan sosial tersebut akan mampu meningkatkan strategi koping pada penderita stroke sehingga penderita merasa bahwa dirinya masih dibutuhkan, diperhatikan, dan merasa bahwa dirinya tidak berbeda dengan manusia yang lain.

Menurut Tatali (2018), Dukungan keluarga tinggi dengan tingkat aktivitas ketergantungan sebagian. Hal ini disebabkan oleh karena penderita pasca stroke tersebut mengalami ketakutan untuk bergerak ataupun beraktivitas secara mandiri. Alasan lain yang menyebabkan responden tidak mandiri yaitu penderita pernah terjatuh ketika berlatih atau beraktivitas terutama berjalan dan kejadian terpeleset dikamar mandi sering terjadi, sehingga hal tersebut menjadi trauma tersendiri bagi orang dengan pasca stroke untuk bergerak ataupun beraktivitas. Hal ini menyebabkan pasien tersebut yang seharusnya mandiri sudah bisa melakukan aktivitas dengan mandiri menjadi terhambat sehingga memerlukan bantuan dari orang lain atau keluarga dalam beraktivitas.

Menurut asumsi peneliti dukungan sosial adalah rasa simpatik dan peduli yang ditunjukkan orangorang di sekitar penderita stroke dalam menghibur, menolong dan memotivasi penderita agar moralnya tidak menurun dan semangat kembali untuk sembuh serta merasa berguna bagi keluarga dan lingkungan sekitar penderita.

Dengan adanya dukungan sosial terhadap pasien stroke dapat meningkatkan kembali rasa percaya dirinya sehingga pasien stroke tidak merasa sendiri karena adanya dukungan sosial dari keluarga yang cukup atau bahkan tinggi, masyarakat dan teman sebaya dengannya. Maka, pasien dapat meningkatkan semangat, kenyamanan 
dan rasa percaya diri penderita stroke dalam proses perawatan

Dukungan dari orang-orang sekitar yang berupa kepercayaan dapat memberikan pengaruh yang kuat bagi seseorang. Apabila seseorang memperoleh dukungan sosial berupa perhatian maka individu lebih merasa percaya diri. Dukungan dapat memberikan rasa aman, rasa dihargai, dicintai dan mengurangi kecemasan yang mereka rasakan selama proses perawatan.

\section{Tingkat Kecemasan}

Hasil penelitian didapatkan bahwa lebih dari sebagain responden merasakan kecemasan sedang yaitu (55\%), selanjutnya ada (40\%) merasakan kecemasan ringan dan hanya (5\%) yang merasakan kecemasan berat pada pasien stroke di Rumah Sakit Stroke Nasional Bukittinggi.

Sedangkan menurut Namora Lumongga Lubis (2009), kecemasan adalah terggangu dari sebuah ancaman. Individu mengalami kecemasan karena adanya ketidakpastian dimasa mendatang. Kecemasan dialami ketika berfikir tentang sesuatu menyenangkan yang akan terjadi.

Menurut Murwani (2008), cemas adalah perasaan takut yang tidak jelas dan tidak didukung oleh situasi. Ketika merasa cemas, individu, individu merasa tidak nyaman, atau takut atau mungkin memiliki firasat akan ditimpa malapetaka padahal ia tidak mengerti mengapa emosi yang mengacam tersebut terjadi.

Sedangkan menurut Murdianingsih \& Ghofur Dalam Nirwana (2016) kecemasan merupakan suatu keadaan dimana seseorang mengalami gangguan alam perasaan yang ditandai dengan perasaan ketakutan atau kekhwatiran yang mendalam dan berkelanjutan, tidak mengalami gangguan dalam menilai realitas masih baik, kepribadian masih tetap utuh (tidak mengalami masalah kepribadian), perilaku dapat terganggu tetapi masih dalam batas-batas normal.

Menurut penelitian yang dilakukan oleh Hawari (2013), kecemasan (ansietas/anxiety) adalah gangguan alam perasaan (affective) yang ditandai dengan perasaan ketakutan atau kekhawatiran yang mendalam dan berkelanjutan, tidak mengalami gangguan dalam menilai realitas (Reality Testing Ability/RTA, masih baik), kepribadian masih tetap utuh (tidak mangalami keretakan kepribadian/splitting of personality), 
perilaku dapat terganggu tetapi masih dalam batas-batas normal.

Menurut Zakiah Daradjat (2010) , mengatakan kecemasan berupa penyakit dan terlihat dalam beberapa bentuk. Kecemasan ini disebabkan oleh hal yang tidak jelas dan tidak ada berhubungan dengan apapun yang terkandang disertai dengan perasaan takut yang mempengaruhi keseluruhan kepribadian.

Menurut peneliti tingkat kecemasan adalah perasaan sedih, emosi yang tidak stabil, cemas, khawatir, rendah diri dan merasa tidak berguna yang dirasakan oleh seseorang yang didiagnosa penyakit seperti stroke, sehingga menyebabkan hilangnya semangat hidup dan dapat merubah kepribadian dan juga memperlama penyembuhan penyakit yang dideritanya.

Oleh karena itu, untuk mengurangi kecemasan pasien stroke memerlukan dukungan sosial yang tinggi terutama keluarga. Kekuatan diri pasien akan meningkat dengan adanya dukungan tesebut.

\section{Dukungan Sosial dengan Kecemasan}

Berdasarkan hasil analisa bivariat diketahui hasil analisis hubungan antara dukungan sosial dengan tingkat kecemasan pada pasien stroke yaitu diperoleh keseluruhan (100\%) pasien yang kurang mendapat dukungan sosial merasakan kecemasan berat. Selanjutnya ada (64\%) dukungan sosialnya cukup merasakan kecemasan sedang, Sedangkan penderita stroke yang yang mendapat dukungan sosial yang tinggi ada masing-masing (50\%)yang merasakan kecemasan sedang dan kecemasan ringan.

Berdasarkan hasil uji statistik menunjukkan bahwa terdapat hubungan yang signifikan antara dukungan sosial dengan kecemasan pada pasien stroke di Rumah Sakit Stroke Nasional Bukittinggi tahun 2018 ditandai dengan nilai $P 0,000<\alpha(0,05)$, yang artinya $\mathrm{H}_{0}$ ditolak.

Penelitian ini sejalan Rahmawati (2013) menunjukkan nilai $\mathrm{p} \leq \alpha=0,05$ yakni ada hubungan antara tingkat kecemasan pada pasien stroke dengan nilai $\mathrm{p}=0,003$, sehingga nilai $\mathrm{p} \leq \alpha=$ 0,05 yang menyatakan bahwa dukungan sosial dapat memberikan kenyamanan fisik dan psikologis kepada individu, hal tersebut dapat dilihat dari bagaimana dukungan sosial mempengaruhi kejadian dan efek dari keaadaan stress atau cemas. Kondisi ini dijelaskan bahwa berinteraksi dengan orang lain dapat memodifikasi atau mengubah 
presepsi individu mengenai kejadian tersebut, dan itu akan mengurangi potensi munculnya rasa kecemasan baru dan rasa cemas yang berkepanjangan.

Penelitian menurut Hasan (2013), dengan $p=0,000(\alpha \leq 0,01)$ yang berarti ada hubungan positif yang signifikan antara dukungan social dengan strategi coping pada penderita stroke. Penderita stroke juga termasuk makhluk sosial, strategi coping yang dimunculkan pada penderita stroke akan sangat dipengaruhi pula oleh dukungan lingkungan sekitarnya baik secara moril maupun materil, dan dukungan ini akan menjadi lebih penting untuk membangun kepribadian penderita ketika menghadapi permasalahan atau tekanan yang menurut penderita sulit dihadapi. Dukungan antar individu dengan lingkungan sosial bersifat timbal balik, dimana lingkungan mempengaruhi individu dan individu mempengaruhi perkembangan lingkungan.

Penelitian ini juga sejalan dengan Isnawati (2013), adanya hubungan yang bermakna antara dukungan keluarga dengan nilai $p=0,004 \quad(\alpha \leq 0,005)$ menyatakan dukungan sosial merupakan bantuan atau dukungan yang diterima individu dari orang-orang tertentu dalam kehidupannya, diharapkan dengan adanya dukungan sosial maka seseorang akan merasa diperhatikan, dihargai, dan dicintai. Dengan pemberian dukungan sosial yang bermakna maka seseorang akan mengatasi rasa cemasnya terhadap pembedahan yang akan di alaminya.

Menurut Masyithah (2012), ada hubungan yang signifikan antara dukungan sosial dengan penerimaan diri ditunjukkan dengan $p$-Value $0,000(\alpha \leq$ 0,05) maka Ho ditolak dan Ha diterima - Bentuk dukungan sosial yang diberikan oleh lingkungan sosial dapat berupa kesempatan untuk bercerita, meminta pertimbangan, bantuan nasehat, atau tempat untuk mengeluh. Selain itu, lingkungan dapat memberikan dukungan sosial berupa perhatian, bantuan materil dan spiritual serta penghargaan dari lingkungannya. Dukungan sosial akan sangat diperlukan oleh penderita pasca stroke karena akan mengurangi ketegangan psikologis dan menstabilkan kembali emosi penderita pasca stroke.

Menurut Hawari (2011), dengan $p$ $=0,000(\mathrm{p}=0,01)$ yang berarti ada hubungan positif yang signifikan antara dukungan social pada penderita stroke. Penderita stroke juga termasuk makhluk 
sosial, strategi coping yang dimunculkan pada penderita stroke akan sangat dipengaruhi pula oleh dukungan lingkungan sekitarnya baik secara moriil maupun materil, dan dukungan ini akan menjadi lebih penting untuk membangun kepribadian penderita ketika menghadapi permasalahan atau tekanan yang menurut penderita sulit dihadapi. Dukungan antar individu dengan lingkungan sosial bersifat timbal balik, dimana lingkungan mempengaruhi individu dan individu mempengaruhi perkembangan lingkungan.

Menurut peneliti hubungan dukungan sosial dengan kecemasan pasien stroke sangatlah erat sekali. Karena pada pasien stroke, memiliki perasaan tidak berguna dan dihantui ketakutan akan kelumpuhan, sehingga dukungan sosial dari keluarga dan lingkungan sekitarnya sangat membantu untuk menghilangkan rasa cemas tersebut, contohnya dengan mengajak penderita stroke untuk berdiskusi ringan tentang keahlian yang mereka miliki akan membuat rasa cemas tidak akan berguna lagi akan berkurang.

Dukungan yang muncul melalui ekspresi penghargaan positif terhadap orang lain, memberikan semangat atau

memberikan persetujuan mengenai ideide/perasaan individu. Dukungan instrumental yaitu sebuah sumber pertolongan praktis dan konkrit, diantaranya ketaraturan menjalani terapi, kesehatan penderita dalam hal kebutuhan makanan dan minum, istirahat dan terhindarnya penderita dari kelelahan. Dukungan informasional yaitu dukungan yang dapat diberikan berupa nasehat, pengarahan, saran, umpan balik mengenai bagaimana seseorang bertindak.

Dukungan keluarga adalah keikut sertaan keluarga untuk memberikan bantuan kepada salah satu anggota keluarga yang membutuhkan pertolongan baik dalam hal pemecahan masalah,pemberian keamanan dan peningkatan harga diri. Keluarga memiliki beberapa bentuk dukungan yaitu dukungan emosional yaitu melibatkan ekspresi cinta, kepercayaan, dan perhatian kepada orang lain, serta mendengar dan di dengar saat mengungkapkan perasaan.

Disarankan kepada keluarga dapat memberikan dukungan penuh pada pasien stroke maka tingkat kecemasan pada pasien stroke semakin berkurang. Karena dukungan dapat membantu dan mempercepat dan penyembuhannya. 
KESIMPULAN

Berdasarkan analisis data terdapat hubungan yang signifikan antara dukungan sosial dengan kecemasan pada pasien stroke

\section{REKOMENDASI}

Hasil penelitian ini disarankan kepada perawat/petugas rumah sakit

DAFTAR PUSTAKA

Antari, A., \& Malekpour, F. (2014). The Role of Self-Efficacy and Social Support in Predicting Depression Symptoms in Diabetic Patients . Iranian Journal of Dukungan social , Volume 6, Number 3, 126-130.

Donner, N.C., Lowry, C.A., 2013. Sex Differences in Anxiety and Emotional Behavior. Pubmed. 5:601-602

Gina.A (2015) diakses dari https://www.scribd.com/document /328693878/KuesionerDukungan-Teman-Sebaya

FK UNRI. Riau . (2008). Faktor faktor yang berhubungan dengan kejadian hipertensi pada pasien yang berobat di poliklinik dewasa puskesamas bangkinang

Ginsberg, Lionel. (2009). Neurologi Lecture Notes. Jakarta : Erlangga Medika Series

Hawari, D. (2011). Psikiatri Menajemen Stress, Cemas \& Depresi. Jakarta : FK UI

Hasan, nur . (2013). Hubungan antara dukungan sosial dengan strategi coping pada penderita stroke untuk lebih aktif melibatkan keluarga dalam merawat pasien stroke sehingga meminimalkan kecemasan pasien. Perawat juga lebih aktif melakukan tindakan manajemen ansietas seperti teknik relaksasi, distraksi dan modifikasi lingkungan.

Rsud Dr. Moewardi surakarta. Program studi psikologi fakultas ilmu kesehatan Universitas sahid Surakarta

(2013). Hubungan Antara Penerimaan Diri dan Dukungan Emosi dengan Optimisme pada Penderita stroke Aktif PERSADIA (Persatuan stroke Indonesia) Cabang Surakarta. Jurnal Ilmiah Psikologi Candrajiwa Vol. 2 No. 2, 60-74.

Hendry. (2014). Perancangan Clustering Data Menggunakan Algoritma K-Means Berbasis Heatmap (Studi Kasus : Propinsi Papua Barat).

Isnawati, Dian \& Suhariadi Rendi. (2013). Hubungan antara Dukungan Sosial dengan Penyesuaian Diri Masa Persiapan Pensiun pada Karyawan PT Pupuk Kaltim. Jurnal Psikologi Industri dan Organisasi. Vol. 1, Februari 2013,Hal. 16.Departemen Psikologi Industri dan Organisasi Fakultas Psikologi Universitas Airlangga

Junaidi, Iskandar. (2011). Panduan praktis Pecengahan dan Pengobatan Stroke. PT Bhuana Ilmu Populer . Jakarta. 
Kholil Lur, Rahman. (2010). Kesehatan Mental. Purwokerto: Fajar Media Press.

Nabyl R.A. (2012). Deteksi Dini Gejala Pengobatan Stroke. Yogyakarta : Aulia Publishing

. (2012). Latihan gerak terhadap keseimbangan pasien stroke non hemoragik di rumah sakit dr. Moerwardi Surakarta. http://journal.unnes.ac.id/nju/inde x.php/kemas/article/ diunduh pada tanggal 23 Desember 2014.

Mardhiah, Ainal. (2015). Persepsi Pasien Stroke Tentang Dukungan Pasangan Di Banda Aceh Perception of Stroke Patients to the Spousal Support Case Study in Banda Aceh: Banda Aceh

Masyithah D. (2012).Hubungan Dukungan Sosial Dan Penerimaan Diri Pada Penderita Pasca Stroke : http://digilib.uinsby.ac.id/9770/1/j iptiain--dewimasyit-10330-1hubungan-e.pdf.

Meschia., et al. (2014). Guidelines for the Primary Prevention of Stroke A Statement for Healthcare Professionals From the American, Heart Association/American Stroke Association. Diakses tanggal 5 April 2018 , dalam http://stroke.ahajournals.org

Mustamir, Pedak. (2009). Tentang Jenis- Jenis Kecemasan Metode Supernol Menaklukkan Stres. Jakarta : Hikmah Publishing House.

Muzdalifah. (2009). Hubungan antara Dukungan Sosial dari Keluarga dan Motivasi Bertahan Hidup pada Penyandang Cacat. Skripsi (tidak diterbitkan)
Surabaya :Fakultas Psikologi Airlangga.

Pinto, S., \& Caple. C, (2010). Stroke: Risk and protective factor. Glendale, California : Cinalhl Information Systems.

Pinzon, R. \& Laksmi Asanti. (2010). Awas Stroke. Pengertian, Gejala, Tindakan, Perawatan dan Pecengahan. Hal. 20. Yogyakarta :Penerbit Andi.

Potter, P. A \& Wiyono, A. G. (2013). Fundamental of Nursing Edisi 7. Jakarta: Salemba Medika.

Purnomo, H. (2010), Ganguan Tentang Penyebab Stroke .Yogyakarta:Buana Pustaka

R.A Nabyl.(2012). Deteksi Dini dan gejala dan pengobatan stroke, solusi hidup sehat bebas stroke.Yogyakarta : Aulia Publishing.

Rahmawati , Andhika. (2007). Hubungan Dukungan Keluarga Dengan Tingkat Kecemasan Akibat Hospitalisasi Pada Anak Usia Sekolah Di Bangsal L Rsup Dr. Soeradji Tittonegoro Klaten Jurnal Kesehatan. Yogyakarta :Surya Medika. Diperoleh pada tanggal 12 Oktober 2013 dari http://www.skripsistikes.wordpres $\underline{\text { s.com }}$

Rohardija, R., Komariah, M., \& Dian, A. (2012). Konsep Diri Pada Pasien Stroke Ringan di Poliklinik $S$ a $r a \quad f \quad R S U D$ Sumedang.

Sarfino, E.P (2013). Dampak kecemasan Healthy Psychology : biopsychsocial interactions (5th ed.). new york : John Wiley \& Sons, Inc 
Sur yaningsih. (2013). Hubungan dukungan keluarga dengan depresi pada pasien penyakit ginjal kronik di ruangan hemodialisa blu RSUP Prof. Dr. $R d$. Kandou manado : Manado

Steph, Elle, ehow Blog. (2010). Dalam Principles and Methods of Research, (2006) Ariola et. at

Stuart, G,W, \& Sundeen, S.J. (2013). Buku Saku Keperawatan Jiwa, Edisi 5. Jakarta : EGC.

Suyanto. (2009). Tingkat Kecemasan Penderita Hipertensi. Universitas Sanata Dharma Yogyakarta.

Syilvia, M, Lorranel Orrane (2009), Factor Resiko Stroke. Edisi $6 \mathrm{Vol}$ 2. Konsep khusus proses penyakit Jakarta : EGC

Tatali, Abdul Jalil. (2018). Hubungan dukungan keluarga dengan tingkat kemandirian activity daily living (ADL) pada pasien pasca stroke di Poliklinik neurologi RSU
Gmim Pancaran Kasih Manado:

Manado

Taylor, S.E., Peplau, L.A., dan Sears, D.O. (2009). Psikologi S osial. Edisi Kedua belas. Alih Bahasa: Tri Wibowo, B.S. Jakarta: Kencana Prenada Media Group.

Videbeck, S. L., (2008). Buku Ajar Keperawatan Jiwa Jakarta : Buku Kedokteran. EGC.

World Health Organization (2012). Ageing and Life Course. http://www.who.int/ageing/about/ facts/en/ Diakses tanggal 14 april 2014 jam 12.05 WITA.

Yayasan Stroke Indonesia, (2012). Indonesia tempati urutan pertama didunia dalam jumlah terbanyak penderita stroke. Diambil pada tanggal 3 Maret 2014 dari http://www.yastroki.or.id/read.ph $\mathrm{p} ? \mathrm{id}=3$ 